Marquette University

e-Publications@Marquette

College of Nursing Faculty Research and

Publications

Nursing, College of

$3-1-2006$

\title{
Understanding Sexual Abstinence in African American Teens
}

Kristin Haglund

Marquette University, kristin.haglund@marquette.edu

Accepted version. MCN: American Journal of Maternal Child Nursing, Vol. 31, No. 2 (March/April 2006): 86-92. Permalink. (C) 2006 Lippincott Williams \& Wilkins, Inc. Used with permission. 


\section{Understanding Sexual Abstinence in African American Teens}

By Kristin Haglund

Purpose: To explore the perspectives of teenage girls on how life contexts influenced sexuality and sexual abstinence.

Study Design and Methods: A qualitative descriptive study with a convenience sample of 14 sexually abstinent African American adolescent females who were interviewed to obtain their life histories. Narrative analysis was used to identify unique and common experiences and to develop themes.

Results: For these participants, being abstinent was a way to demonstrate their emerging identities as adult women. They described themselves as faithful, unique persons who defied negative stereotypes, avoided risky situations, wanted to be strong women like their mothers and grandmothers, and were selective about their friends. The primary challenge to abstinence was their degree of vulnerability to sexual harassment, romantic partner pressure, and female peer pressure.

Clinical Implications: Abstinence is a complex state of being that is influenced by a variety of contexts, develops over time, and is consciously chosen. Maintaining abstinence requires effort and a variety of skills. While these young women were cognitively familiar with reasons why they should refrain from sex, nurses may still assist youth with being abstinent by providing ongoing teaching and specific dialogue on how to refrain from sex.

In the minds of many persons, avoiding sexual activity is the best way for adolescents to prevent negative consequences in their lives; in pursuit of this end, the federal government has committed millions of dollars to abstinence education. Across the nation, various groups have put forth efforts to increase abstinence among adolescents, mostly through abstinence education programs. Some of these programs have shown increases in adolescents' knowledge regarding consequences of sexual activity and how to prevent such consequences (Barnett \& Hurst, 2003; Basen-Engquist et al., 2001; Siegel, Aten, Roghmann, \& Enaharo, 1998). However, very few interventions have resulted in significant increases in abstinence behavior (DiCenso, Guyatt, Willan, \& Griffith, 2002). Thus, the challenge in an era when HIV rates are increasing in youth, sexually transmitted infections remain common (Basen-Engquist et al., 2001), and teenage pregnancy (although rates have declined) continues (Martyn \& Hutchinson, 2001) is to convert adolescent knowledge about abstinence to abstinence behavior.

There are no clear answers to explain why interventions to increase abstinent behavior 
have not been successful. This study, therefore, was designed to find some answers through talking to youths who are currently practicing ab-stinence. The aim was to find out what they have done to be successful at their efforts, for few researchers have investigated factors that challenge youths to refrain from sexual activity (Kelly \& Morgan-Kidd, 2001; Martyn \& Hutchinson, 2001; O'Sullivan \& Meyer-Bahlburg, 2003). Increased understanding about factors that influence abstinence (from the perspectives of adolescents) may improve existing efforts and contribute to the development of innovative interventions.

\section{Study Design and Methods \\ Conceptual Perspective}

The life-span approach to human development was the conceptual perspective for this study. As described by Baltes, Reese, and Lipsitt (1980) in their classic work, development is viewed as a lifelong process occurring in multidirections and within biologic, environmental, social, and cultural contexts. Sexuality is one aspect of human development that is particularly salient for adolescents. Sexuality includes a person's ideas about masculinity and femininity, personal gender identity and how it is expressed, and how men and women relate in general and in intimate relationships. Sexual abstinence is an expression of one's sexuality and identity.

\section{Sample}

This study included sexually abstinent African American female adolescents. The author felt it was important to study this population because, historically, negative sexual stereotypes of African women were used to justify and to perpetuate their exploitation and oppression by Caucasian Europeans and later by Caucasian Americans (Taylor, 1999). Today, African American women and teenage girls are still too often stereotyped as having uncontrolled sexuality, low sexual morals, and too many children (Taylor, 1999). This study took an alternative view, examining African American girls' descriptions of their experiences with abstinence.

A convenience sample was recruited from September 2000 through March 2001. Screening for eligibility was done in a private setting with only the teen and the researcher or a staff person trained to screen being present. Young women who agreed to be interviewed for the study also agreed to parental consent for participation. Four participants were recruited from a pediatric primary healthcare center and nine from a high school-based clinic. One participant was a peer counselor in an abstinence education program for middle-school students. After interviewing the 14th participant, recruitment was closed as new themes were not emerging. Protection of human subjects approval was granted from the appropriate boards. 


\section{Method}

This was a part of another qualitative descriptive study that aimed to discover how the participants defined sexual abstinence (Haglund, 2003). To explore how events of the past and those occurring over a lifetime had influenced the participants' present state, the life history method was selected for data collection. Family demographic information was obtained from the guardian or parent during the consent process. All other data were collected during two, approximately 1-hour, tape-recorded, semistructured, private interviews. Interviews were conducted with each participant on 2 separate days.

Life histories were collected using an interview guide. Open-ended questions were arranged in chronologic order from early childhood to the present. Participants were asked about their families (such as family composition, what members were like and how they interacted with each other); about themselves (such as their strengths, aspirations, and talents); and about their school and friends (such as their favorite subjects, school environment, what their friends were like, and what activities they did together). Questions about religiosity were asked (such as faith and their involvement in church), and questions about love and romance were explored (dating and romantic partners). The participants were asked specific questions about abstinence such as, "What does being sexually abstinent mean to you?", "Give me an example of the kind of things that help you [or make it hard for you] to stay abstinent", "What do your friends think about sex and abstinence?" The researcher asked follow-up questions, and the participants spoke about aspects of their lives that the interview guide questions had not addressed.

\section{Analysis}

Taped interviews were transcribed, reviewed to delete identifiers, and screened for errors, and then observations from the interviews (such as the participant's gestures or expressions) were added as notes. Narratives, which included stories and descriptive passages, were identified within the transcripts. Each narrative was condensed into an adequate paraphrase, which became the first unit of analysis (Hall, Stevens, \& Pletsch, 2001). Condensing the data was a way to manage the lengthy narratives and to increase rigor because participants identified the most important aspects of their stories rather than the researcher. To create the paraphrases, each narrative was first divided into individual clauses, which were then placed on separate lines (Haglund, 2003). The researcher compared the emphasis of each line with the others to identify the portions of the narrative that were most heavily emphasized by the participant. The emphasized portions of the narratives were combined to create the paraphrases. Verbatim quotations that captured the essence of a story were included in the paraphrases as specific 
examples.

The paraphrases were coded with labels corresponding to the major factors including family, self, and school. As data were examined, new codes were developed and existing codes were modified and regrouped. Data within codes were compared across participants. When examining coded data, the researcher referred to participants' actual words to ensure that the emerging interpretations were consistent with their stated experiences. Eventually, two major themes were identified: (1) development of sexual identity and (2) challenges to abstinence.

In qualitative research it is important to pay attention to sources of potential bias, which in this study included differences between the researcher and participants in terms of ethnicity, age, and education. To ensure that the interpretations were grounded in the data, personal bias was overtly examined through the use of an audit trail, consultation with researchers who possessed related expertise, and confirmation from the participants (Anastas, 2004). After reading sections of the findings, participants indicated minor clarifications but stated that overall their experiences were accurately described.

\section{Results}

\section{Description of Participants}

Fourteen females ranging in age from 15 to 18 years participated. The mean age was 16.4 years. One (7\%) participant described herself as African-Jamaican and 13 (93\%) self-identified as being African American or black. Nine (64\%) participants called themselves abstinent and five (36\%) described themselves as not sexually active. Twelve (86\%) participants had never had intercourse although 11 (79\%) had had boyfriends. Two participants had been sexually active but had purposefully stopped engaging in intercourse 2 to 4 years ago and now defined themselves as abstinent.

Family composition included two-parent, one-parent, and guardian-headed households. All of the participants had siblings. Three (21\%) participants had siblings who had been a teen parent. The families of eight (57\%) participants had incomes below the 2000 federal poverty level. Thirteen (93\%) belonged to a variety of Protestant Christian religious denominations and one $(7 \%)$ said that she had no religion. Of the 13 , nine $(64 \%)$ regularly attended religious services

\section{Theme I: Development of Sexual Identity}

For the participants, being sexually abstinent was a way to demonstrate their emerging identities as adult women. The participants described themselves as (a)"faithful," (b)“unique," (c) "defying negative stereotypes," (d) "want to be like my mother/grandmother," and (e)"selective 
about friends."

\section{(a) "I Am a Faithful Person"}

Nearly all of the participants professed faith in a personal, universal God, with some being more enthusiastic about their faith than others. Some participants expressed ambivalence, stating that they believed, but their faith and worship did not occupy a large part of their attention or energy. For the others, faith in God was the foundation for their lives as Christians. Seven of the participants said that they deliberately took actions to live a "Christian life," including attending church, being abstinent, and trying to live according to bible principles. They were confident that their faith and their Christian lifestyle would bring them eternal life in heaven and God's help on earth.

\section{(b) "I Am a Unique Person"}

The participants described themselves as being unique persons in a variety of ways, including:

1. maturity in thought and action,

2. being abstinent,

3. consciously defying negative stereotypes, and

4. because they purposely avoiding risky situations.

Five $(36 \%)$ of the participants said that they were more mature than other teens their age for a variety of reasons. Some felt that socializing more often with their older siblings and their siblings' friends led them to act older than their actual age. Some said that enduring family hardships caused them to mature early. When one participant was 7 years old, she started providing care for her grandmother who had diabetes. She said: "I was always mature for my age...I don't think I really ever had like a normal childhood, I always had big responsibilities.... I'd say when I was 7 or 8 my grandmother started getting real sick so I used to always take care of her... The nurses that would come over, they'd say 'she's too young' but it wasn't nothing to me."

This sense of maturity supported their abstinence. They felt that because of it, they did not get taken in by the boys' lines or succumb to peer pressure. They also felt that having sex as a teenager was an immature behavior and therefore not appropriate for them. The participants felt pleased when others said that they acted mature. A 15-year-old said, "Mostly what I like about the way I am, is how strong I am, and how people tell me how strong I am or how mature I'm getting for my age." Abstinence was one way they demonstrated their maturity and compliments motivated them to continue.

Being abstinent was also a way that they demonstrated their uniqueness; they were different from other teenage girls and they were proud of that. All of the participants expressed 
that they had actively chosen to be abstinent, and that they told others about their choice. They would tell a prospective boyfriend in the beginning of the relationship that if he wanted sex, he had better find someone else. As one 15-year-old said, "Because I let the person know right out of hand the type of person I am, so don't come at me, don't disrespect me, I'll let you know right ahead, so none of that will go on later." In response to refusing sexual advances at school, some boys would call them derogatory names. The participants said that they did not care what names they were called; it strengthened their resolve to remain abstinent. They were motivated to remain abstinent to continue to be different from other girls and to act in a better way.

\section{(c) Avoiding Negative Stereotypes}

Abstinence was linked to their identity as unique African American women and their desire to avoid negative stereotypes. Three said that they were abstinent to be positive examples of African American persons. They felt that many people had negative stereotypes of African American people and they wanted to show that the stereotypes were not true. One 15-year-old said: "Some people think that African-Americans can't do too much with their life. They do drugs and have a lot of sex and do all of that. Some racist people think black people are just all bad and when they see people like us, girls like me and my sister, not doing all that stuff, maybe they think that all black people aren't like that. So, l'm proud of being black."

Finally, the participants felt that they were unique because they purposefully avoided risky situations in which they could get into trouble. An almost 18-year-old participant described herself in this way: "If you tell me well such and such is going to happen and it's bad, I'll say l'm not going to do that. Because l'd rather let somebody else tell me what's going to happen than have me experience it for myself because it might hurt me in the long run so I just avoid it altogether." Many of the girls said that they ignored certain people or certain words to avoid fighting. All of the participants felt that avoiding sex prevented negative consequences and trouble.

Ten $(71 \%)$ of the participants said that one of the main reasons for their abstinence was to avoid pregnancy and parenthood. Seven (50\%) of the participants' mothers had their first babies when they were unmarried and between 16 and 19 years old. The participants' mothers used their experiences to teach their daughters to avoid sex and pregnancies as teenagers. The participants' took their mothers' words to heart. As one 17-year-old said, "....My mother had me when she was 17. I'm trying to do everything that she didn't do, be like the opposite of her. I'm going to break the generation cycle."

In addition to firsthand experience of their mothers' challenges, the participants also witnessed the struggles of their classmates and siblings who became teen parents. They learned 
from these living examples that teen parenthood introduced financial struggles and increased responsibilities, decreased time to spend having fun, interfered with school, and disappointed families.

\section{(d) "I Am Becoming a Woman Like My Mother and Her Mother"}

Mothers were the family members the participants talked about the most. In most cases, mothers were the center of their lives, the persons who cared for and protected them, and provided emotional and economic support. The participants respected accomplishments of their mothers such as returning to college as an adult, raising a large family, and raising successful children as a single parent. They expressed admiration for their mothers who survived hardships such as poverty, single parenthood, and physical abuse. One 16-year-old said: "She [her mother] had to struggle to keep us fed, struggle to keep us clothed, to keep the roof over our heads. But all of us have grown up to be intelligent, bright, and outgoing kids and no one would ever thought that we would've ended up like that because of what we've gone through."

Of all grandparents, the maternal grandmother was most consistently, actively involved with the participants' families. In most families, she had a vital role as the safety net for the family. Nine $(64 \%)$ of the participants had lived with their mothers in their grandmothers' homes. In some cases the grandmother assumed a coparent role when the participants' fathers were absent. Over the participants' lives, the grandmothers continued to share their resources with the participants and their families to keep them together, healthy, and safe. The participants viewed their mothers and grandmothers as role models of adult women who were strong, responsible, reliable, independent, smart, and mature. Being abstinent was a way for the participants to show that they were becoming women like their mothers and grandmothers.

The participants' feelings about their mothers led them to follow their mothers' rules even when they did not like them. Following their mothers' rules contributed directly to maintaining abstinence, as the rules were often designed to either prevent the participants from having boyfriends or to prevent prolonged, unsupervised interactions with boys and boyfriends. The mothers clearly conveyed that they disapproved of their daughters having sex while they were adolescents. As one young woman said, "I want her to say I know for a fact by the age of 18 none of my kids had babies. I don't want to be the one to disappoint my mother so I choose not to have sex."The participants did not want to have sex because they did not want to disobey or disappoint their mothers.

\section{(d) "I Am Selective About My Friends"}

The participants chose girlfriends who were also sexually abstinent. The friends reminded each other that they were abstinent and that they should stay that way. They became upset 
when they suspected or knew that a friend had become sexually active. Six (43\%) participants said that they had a friend who had gone "wild" and had tried to influence her to stop having sex. Once their friends started having sex, they did not spend as much time with the participants, leading the participants to feel hurt. However, the participants did not become sexually active to be like their friends or to preserve the friendships; rather, they remained true to their identity as abstinent persons.

\section{Theme II: Challenges to Abstinence}

There were three primary sources of challenge to abstinence: vulnerability to sexual harassment, romantic partner pressure, and female peer pressure.

\section{(a) Sexual Harassment}

The participants described high school as a place with an atmosphere of hypersexualized male-female relationships. Every day, some of the boys made offensive sexual remarks. The remarks were propositions for sex such as "let me hit that," requests for oral sex, and comments or insults about girls' appearances. The participants responded by ignoring the remarks, saying no, or making sarcastic retorts. Participants felt that the boys made sexual remarks because they were immature. The participants were not surprised by this behavior and rarely complained to their teachers or other adults about it. Once rejected, boys would move on to harass another girl, some would say bad things about the girl who refused, and some would persist in their attempts as if by badgering her, she would eventually relent. As one participant said: "This one boy-he just won't accept no for an answer. I said, 'well what do I have to say to you to get it through. It's not gonna happen ever.' He's like, 'well it is. You have to accept the electricity between the two of us. "'Sometimes boys taunted a girl for being too afraid to have sex. In one case, "They asked my friend if she wanted to and she said 'no.' They said, 'well are you scared? You're scared it's going to hurt, you're scared of this, you're scared of that."' Other tactics included enlisting a friend or family member to convey the boy's desire, or befriending the girl first and pressuring her for sex later.

Boys did not experience negative consequences for their behavior. Their male peers admired them and the girls either went along with it or walked away. The boys were not punished at school as the teachers felt that they had to catch the boys in the act of harassment rather than acting on the girls' reports. "Every time I tell the teachers they don't do nothing about it. They say if they didn't see it, they can't do anything,"said a 15-year-old participant.

\section{(b) Romantic Partner Pressure}

Boyfriends challenged abstinence by asking for sex. In some cases, this request was a 
condition that eventually ended the relationship. Some participants considered having sex to keep their relationships going, but did not, and were ultimately glad of their decisions. The participants said that boys often bragged about having sex. They received positive regard from other boys, whereas girls who had had sex received negative attention from the other male and female students. They were labeled a "ho" or a "jump down," both insults implying that the girls were promiscuous. The participants thought that such girls had sex due to a character flaw such as lack of self-esteem, desire for attention, or because they were "fast." While the participants did not approve of the boys' behavior, they seemed to expect it. As one participant explained, “Well in my point of view, boys, that's what they want anyway. Because some boys, they're raised like that. And they have no problem asking a girl when are you going to give me some."In the participants' opinions, it was up to the girls to resist. Girls who could not resist more or less deserved to be discussed negatively.

\section{(c) Female Peer Pressure}

Other teenage girls also challenged the participants' abstinence. Sexually active girls sometimes chided the participants that they should have sex, as they did not know what pleasures they were missing. An almost 18-year-old said, "People ask me stupid questions all the time. Like, 'Isn't it hard? Don't you just like want it sometimes? I can't go without having sex. '” In some cases sexually active girls encouraged the participants to have sex to improve their relationships with their boyfriends. Some girls teased the participants about not having sex, calling them "stuck up" or "little kids." The participants often physically avoided these types of girls. They also avoided group conversations about sex to keep their abstinence private to avoid pressure from other girls.

\section{Clinical Implications}

Nurses can use the results of this study to better understand adolescents and their attitudes toward abstinence. By reading the firm views of the young women in this study, nurses can learn additional information to use in their counseling of adolescents in their practice. While nurses should continue to teach youths about the risks associated with premature sexual activity, it is also important to expand that teaching to include lessons on how to be abstinent. Lessons from successful programs such as those in Uganda, where the prevalence and incidence of HIV infections have decreased by teaching and practicing the Ugandan model of HIV risk reduction termed "ABC" for Abstinence, Be faithful (monogamy), and use Condoms (Singh, Darroch, \& Bankole, 2003) should be learned from the literature and then used in counseling. As part of 
comprehensive sexuality education, abstinence may be presented as a strategy to lower sexual risk by decreasing sexual exposures and number of partners.

The teens in this study as well as those in other studies (Martyn \& Hutchinson, 2001) avoided pregnancy to protect their future goals. They valued education and were looking forward to financial independence. When working with youth who have never had sex, or those who have and want to stop, linking avoidance of sexual risk to future aspirations may be a useful tool. Some strategies for this teaching could include providing "how-to" information including teaching skills for maintaining abstinence. Some of these skills are the ones used by the young women in this study: keeping the commitment to abstinence fresh, resisting peer pressure, avoiding or escaping from risky situations, and withstanding daily challenges to become sexually active. Nurses working with these adolescents can assist them to identify the challenges they are experiencing and then tailor teaching to meet their specific needs. Prepare them with the knowledge of how much work may be required, for efforts to remain abstinent are difficult. Guide them toward identifying and valuing the supportive forces and people in their lives and use those positive feelings to solidify their commitment to abstinence.

The barriers to abstinence described in this study were problems in interpersonal relationships. Therefore, nurses can help by teaching young women how to cultivate and participate in healthy interpersonal relationships, emphasizing the development of respectful intimate relationships (O'Sullivan \& Meyer-Bahlburg, 2003). It is essential to also teach principles of friendship such as how to choose friends who have similar values, how to develop supportive friendships, and how to resist unsupportive friends.

This study has shown that being abstinent requires ongoing work on the part of adolescents. Our role is to help youths to be abstinent with ongoing support, education, and dialogue from nurses and other adults who care about teens.

\section{Acknowledgments}

This study was supported in part by grants from the American Nurses Foundation, the Nurses Foundation of Wisconsin, and the Harriet H. Werley Doctoral Student Research Award. The author was designated as a 2000 American Nurses Foundation Scholar. She thanks Leona Vandevusse for her reviews of the manuscript.

Data from this article have not been included in another manuscript.

\section{Biography}

Kristin Haglund is an Assistant Professor, College of Nursing, Marquette University, 
Milwaukee, WI. She can be reached via e-mail at kristin.haglund@mu.edu. The author has no financial interest or affiliation with any organization or company related to the material in this article.

\section{References}

Anastas, J. (2004). Quality in qualitative evaluation. Research on Social Work Practice, 14(1), 57-65.

Baltes, P., Reese, H., \& Lipsitt, L. (1980). Life-span developmental psychology. Annual Review of Psychology, 31, 65-110.

Barnett, J., \& Hurst, C. (2003). Abstinence education for rural youth: An evaluation of the life's walk program. Journal of School Health, 73(7), 264-268.

Basen-Engquist, K., Coyle, K., Parcel, G., Kirby, D., Banspach, S., Carvajal, S., et al. (2001). School wide effects on a multicomponent HIV, STD and pregnancy prevention program for high school students. Health Education \& Behavior, 28(2), 166-185.

DiCenso, A., Guyatt, G., Willan, A., \& Griffith, W. (2002). Interventions to reduce unintended pregnancies among adolescents: Systematic review of randomized controlled trials. British Medical Journal, 324(7351), 1426-1430.

Haglund, K. (2003). Sexually abstinent African American adolescent females' descriptions of abstinence. Journal of Nursing Scholarship, 35(3), 231-236.

Hall, J., Stevens, P., \& Pletsch, P. (2001). Team research using qualitative methods. Journal of Family Nursing, 7(1), 7-31.

Kelly, P., \& Morgan-Kidd, J. (2001). Social influences on the sexual behaviors of adolescent girls in at-risk circumstances. Journal of Obstetric, Gynecologic, and Neonatal Nursing, 30(5), 481-489.

Martyn, K., \& Hutchinson, S. (2001). Low-income African American adolescents who avoid pregnancy. Qualitative Health Research, 11(2), 238-256.

O'Sullivan, L., \& Meyer-Bahlburg, H. (2003). African-American and Latina inner-city girls' reports of romantic and sexual development. Journal of Social and Personal Relationships, 20(2), 221-238.

Siegel, D., Aten, M., Roghmann, K., \& Enaharo, M. (1998). Early effects of a school-based HIV infection and sexual risk prevention intervention. Archives of Pediatric \& Adolescent Medicine, 152, 961-970.

Singh S., Darroch, J., \& Bankole, A. (2003). A, B, C, in Uganda: The role of abstinence, monogamy and condom use in HIV decline. Occasional Report in the Alan Guttmacher 
Report, 9. Retrieved August 25, 2005, from www.agi-usa.org

Taylor, J. (1999). Colonizing images and diagnostic labels. Advances in Nursing Science, 21(3), 32-45. 


\section{Appendix}

\section{Suggested Clinical Implications}

- Include abstinence education along with sexuality education for adolescents.

- Make teenage clients feel respected and validated by acknowledging their abilities to independently make choices and conclusions.

- $\quad$ Praise youths who have been abstinent for a period of time; compliments and positive feedback about their maturity and abstinence could encourage them to continue.

- $\quad$ Reinforce that abstinence is not a default status but requires choice and commitment.

- $\quad$ Prepare youths with the knowledge of how much work may be required to remain abstinent, and help them to identify the personal value of that effort.

- $\quad$ Guide youths toward valuing the supportive forces and people in their lives; emphasize the importance of having friends who share their values and support their choices.

- $\quad$ Encourage ongoing dialogue between parents and youths about sexuality.

- Teach youths how to cultivate and participate in healthy interpersonal relationships where pressure to do what only one person wants is not tolerated.

- Help adolescent girls to resist the harassment of adolescent boys about their choice to be sexually abstinent. 